IRSH 49 (2004), pp. I I 5-I 2 I DOI: I0.10I7/S002085900300I 408

(C) 2004 Internationaal Instituut voor Sociale Geschiedenis

\title{
A Unified Field Theory for Contention?
}

\author{
DILIP SIMEON
}

Dynamics of Contention purports to show how social movements, revolutions, strike waves, nationalism, democratization, and other types of contention result from "similar mechanisms and processes", and claim that more may be learned by comparative studies than through singular topical study. The authors aim to discover "recurring causal sequences of contentious politics" (p. 4), and to breach topical boundaries as well as the demarcation between institutionalized and noninstitutionalized politics. They define contentious politics as "episodic, public, collective interaction among makers of claims and their objects when (a) at least one government is a claimant, an object of claims, or a party to the claims and (b) the claims would, if realized, affect the interests of at least one of the claimants". ("Interest" is uninterrogated). They go on to say, "roughly translated, the definition refers to collective political struggle" (p. s).

The avowal (p. 5) that "the contentious politics that concerns us is episodic rather than continuous", seems whimsical, especially as "episodes" (p. 24) are defined as "continuous streams of contention including collective claims making that bear on other parties' interests" - a very wide-ranging definition. We are also told of the advantages of "treating an entire stream of confrontations as a single episode" (p. 30). Contentious politics is episodic rather than continuous, and episodes are continuous streams of contention! This is confusing, to put it mildly. The word "episode" means a finite period in the history of something, complete in itself but part of a continuous narrative or series. It does not imply a brief duration. Why does the IsraelPalestine dispute not qualify? But for this unexplained and indeterminate delimitation signified by "episodic"(the authors also exclude "regularly scheduled events such as [...] parliamentary elections"), the conflicts known as the Cold War and the Vietnam War and the conflict in Kashmir would qualify as contentious politics. What of Indian nationalism, which incorporated all of the authors' definitional terms? Were the authors merely trying to reduce the scope of the study? Or would a broader view of "episodic political conflict" affect their theoretical claims?

\section{DEUS EX MACHINA}

"Mechanism" is the most ubiquitous and crucial concept in this book. Mechanisms are defined as "a delimited class of events that alter relations 
among specified sets of elements in identical or closely similar ways over a variety of situations" (p. 24). "Processes" are "regular sequences of such mechanisms that produce similar (generally more complex and contingent) transformations of those elements". The metaphors are derived from Newtonian physics, "mechanisms and processes form a continuum" (p. 27). "Mechanism", to my mind, might serve an enlightening purpose if used sparingly, and with reference to a function of social power and ideological /political control - as in caste systems, the census and colonial ethnography. (Not to mention political science). The controlling structures of state and economy are indeed meant to function in machine-like rhythms. From this standpoint, the use of mechanical metaphors is apposite, as long as we remember that they are metaphors. Demography too, might make use of this metaphor in, say, the study of large-scale population movement - thus pogroms, the Irish potato blight, and waterlogging (Kosi, North Bihar) could be named mechanisms of migration, although there are perfectly suitable alternatives. On the other hand, no social-scientific machinery, howsoever sophisticated, can provide a satisfactory explanatory account for such historical events as the role of Gandhi in the communal politics that unfolded in Calcutta during I9461948, or that of Lenin in revolutionary Russia between April and October I9I7.

Is there is something uniquely comforting about the machine, which results in its recurrent use as a historical and social metaphor? Machines are predictable, controllable, set into motion by professionals, and may be fixed when necessary by experts who manufacture them and know how they function. Experts breathe life into machines and treat them as if they possessed intelligence and volition. In this book, it is the mechanisms that "shape", "concatenate", "operate". "transform", "produce", "drive", and "shed light" (p. I 59). What is the ontological status of something so active and subject-like? The authors say they use paired comparisons "to discover whether similar mechanisms and processes drive changes in substantially divergent periods, places and regimes" (p. 82). What drives the mechanisms? What's the fuel? Or are they self-driven?

By way of exemplifying what their method of "paired comparison of uncommon cases" can accomplish, we are offered some pedestrian observations on the differences between the contexts for social democracy in Russia, as compared to western and central Europe. Then, say the authors,

$[\ldots]$ in the backward conditions of Tsarist Russia, mobilization had to take covert and controlled forms - exactly what Lenin prescribed in What Is To Be Done? The historically unique episode of the Russian Revolution issued in part from a process of mobilization that in turn resulted from specific mechanisms of recruitment, control, and conflict. (p. 83) 
What difference would it make to this sentence, if the word "mechanisms" were substituted by "forms"? (The authors cover their flanks by saying "issued in part"). A great deal of mobilization in I905 and I917, far from being "covert and controlled", took place in the wide open, in soviets and factory committees, mass rallies, and demonstrations. There were a great many political and working-class currents, apart from the Bolsheviks, engaged in mobilization. Their efforts were not connected with, nor did they in any way resemble "exactly what Lenin prescribed". The October Revolution was by no means a foregone conclusion, and whereas Bolshevism (more specifically Lenin's leadership), was crucial to the latter, the authors' "specific mechanisms of recruitment, control, and conflict" had at best a tangential bearing on various other historical determinants of Russia's "historically unique episode". The observation that the "episode" of I917 "issued" from some "mechanism" carries a hint of inevitability and predictability that is completely unwarranted by the historical record. This is just one example of where the book's machinist theoretical vocabulary can lead us.

\section{RAMIFIED CATEGORIES}

The book produces a plethora of highly ramified categories. The authors "advance and attempt to reconcile six distinct claims about creation, appropriation, activation, transformation and suppression of political identities" (p. 56). They describe four, sometimes five "mechanisms of mobilization" (pp. 45, 57) - environmental; attribution of opportunity and threat; social appropriation of existing organizations; framing; innovative collective action. They then outline five steps for modification (pp. 6I -62) of the four-mechanism schema (itself previously presented as a "revised mobilization model" (p. 44). Soon after, we are given four mechanisms for "dynamic processes of contention" - competition, diffusion, repression, radicalization (pp. 67-69). Later we are given four identity forming mechanisms (p. I57) - brokerage, category formation, object-shift, certification. This is qualified by the positing of three subsidiary mechanisms within "the cluster of closely related mechanisms" known as category formation. After a while one loses track.

The authors apply their four identity-forming mechanisms, viz. brokerage, category formation, object-shift, and certification, to communal contention in contemporary India (pp. I48-150). In a few broad strokes, we are told that significant features of the situation correspond to their mechanisms. After this the reader is assured that "Although we need many more causal mechanisms to account for Hindu/Muslim conflict as a whole, our small battery of mechanisms helps explain significant features of the south Asian situation". The suggestion that the deployment of yet more "mechanisms" would "account for Hindu/Muslim conflict as a 
whole" is simultaneously arrogant and inane, especially as the authors display no understanding of the political import of events in south Asia. Witness the phrase "Hindu-Sikh violence" (p. I 29) to describe the massacre that took place in Delhi in 1984 . How would the authors react to a description of east European pogroms as Christian-Jewish violence? Forcing this or that artificially differentiated aspect of a highly complex situation into a cut-and-dried frame of four mechanisms is epistemically presumptuous. Why, for instance, do they use brokerage, a phrase drawn from the universe of commerce, to refer to the phenomenon of political representation? The political function of symbolic assertiveness, the glorification and perpetration of violence by the commanders of identity, the class-caste interests represented by communal politics, the criminalization of the state, and Nazification of the polity are all occluded by this bland description of reified "mechanisms". The authors" "small battery" does not help "explain significant features of the south Asian situation". At best, it tells us how to describe it, and not very fruitfully at that.

On p. I97 we are given three defining "elements" of revolutionary situations: appearance of contenders to exclusive control of state power; support to these by "a significant segment of the citizenry"; and incapacity or unwillingness of the rulers to suppress the contenders. In their elucidation of this schema, the authors concede the need to examine the phrase "significant segment", but seem unaware of the need to interrogate "citizenry". Where the conflict situation is shaped precisely by contending notions of the citizen, surely this, along with the related question of contested constitutions, becomes a crucial issue? But then could we categorize Palestine in 1946-1948 and India at around the same time as being in the grip of a revolutionary situation? Soon thereafter we are told of three key mechanisms in "the process of regime defection" infringement of elite interests, suddenly imposed grievances, and decertification. Each of these is debatable, but they are presented as a formula - "what different mixes of mechanisms shape it (regime defection - DS) - and with what subsequent effects?". The pretence of rigour begins to assume the aspect of rigmarole.

\section{A UNIFIED FIELD THEORY FOR CONTENTION?}

The authors repeatedly claim and disavow any intention to provide an allencompassing theory of conflict, including the Italian students' movement, the disappearance of the USSR, Mexican nationalism, and Indian communalism. They invariably start with a defensive disclaimer, and then do precisely what they have said that they are not doing. Thus,

[...] our aim is not to construct general models of revolution, democratization, or social movements, much less of all political contention [...]. On the contrary, we 
aim to identify crucial causal mechanisms that recur in a wide variety of contention, but produce different aggregate outcomes depending on the initial conditions, combinations, and sequences in which they occur. (p. 37)

So an "aggregate outcome" (whatever that means) is predictable, depending on a mix of mechanisms known to the social scientist. This looks suspiciously like a general model to me. Then again, "we do not seek to isolate general laws of 'collective action' covering social movements, ethnic conflict [...] or revolution [...] instead we search for mechanisms that appear variously combined in all these forms of contention and in others as well" (p. 74). "We are not testing some general theory concerning the origins of contention. Instead we seek to identify important mechanisms that play significant causal parts in a wide variety of mobilization and demobilization" (p. 9I). Sentence number two here sounds suspiciously as if it were overwriting sentence number one. On p. I58, the authors say, "our four mechanisms fall far short of providing a comprehensive model of contentious politics as a whole. We offer them as a sample of identity shaping mechanisms that recur in a wide variety of settings". Soon afterwards we read, "the four mechanisms concatenate differently and produce contrasting results in different settings. Each one operates similarly, however, across a wide variety of eras, regions, social settings and types of contention. We find them recurring in war, revolution, industrial conflicts, nationalism, social movements and democratization".

In their concluding chapter, the authors continue to have their cake and eat it. They claim to have "avoided any claims to create a new general model for all contentious episodes or for particular families of contentious episodes" (p. 305); and insist that they "did not seek to produce new general models or to offer complete explanations". Thereafter, they claim to have "breached barriers among ostensibly different varieties of contention", and to have "searched deliberately for similar causal mechanisms and processes in distinctive forms of processes” (p. 308). The identification of similarity across particularity seems precisely to be the first step towards a general model of causation, especially since this procedure is supposed to provide "much more explanatory leverage" (p. 263).

The authors' attempt at analysing nationalism "as a species of contentious politics" rather than a "sentiment or belief" (p. 228), suggests that there are no other ways of understanding nationalism. Their comparison of Italian unification with Soviet disintegration is intended to demonstrate that "we gain more explanatory leverage by examining the mechanisms that drive a wide range of contentious episodes than by classifying them as if they operated according to their own distinct laws" (p. 228). This implies that such episodes are indeed law-governed (or "driven" by "mechanisms"), the point being that the authors' "laws" 
operate in a far wider space. "Nation" is defined as "a body of individuals who claim to be united by some set of characteristics that differentiate them from outsiders who either strive to create or to maintain their own state". Here "outsider" is treated unproblematically, whereas we have major historical instances of the ideological transformation of insiders into outsiders - we need only remember German Jews and Palestinian Arabs. The authors' definition of "nation-state" as "a political entity whose inhabitants claim to be a single nation and wish to remain one", is equally dubious, for it glosses over the matter of the perversions that popular wishes and claims are subject to in the process of representation. While nationalism may indeed be seen as a form of contentious politics, such a categorization does not explain it any more than definitions that highlight sentiments and beliefs; or the authors' forced subdivisions of sentiment, ideology, and myth. Their observations sidestep the question of nationalism as a milestone in the history of the state, the displacement of statehood by nation-statehood as the fundament of capitalist modernity. Explanations of nationalism might also link nationalist mobilization with the advent of democratic ideology and the disestablishment of legitimation based on divine right.

Dynamics of Contention claims to give readers "a refreshed understanding of familiar processes", and crucially, a new programme for research (p. 37). It would be interesting to know whether the contentious politics school would consider researching the American militaryindustrial complex and oil companies as generators of war, and identity politics (with a focus on Afghanistan in the 1980s) as a mechanism of political control.

The authors systematically depoliticize and denature the significance of crucial historical events, all in pursuit of some universal taxonomy of "contention". Of their four "identity-shaping mechanisms", the authors say, "we find them recurring in war, revolution, industrial conflicts, nationalism, social movements and democratization". This wide canvas could cover contentious processes that take place all the time, and not only in times of high visibility. The concept leaves aside the question of interest formation. In India, the formation and dissolution of identity is an incessant process, with constantly overlapping identities and changes of factional allegiance. The application of a universal mechanical typology, with scores of scientific-sounding categories, leaves us none the wiser as to why these things happen, their historical significance, and their potential for conflict. What is more, they confuse description and classificatory schema with explanation. Their highly convoluted categorial structure might serve the limited purpose of a taxonomy for a pre-analytical breakdown of phases of conflict. That too would presuppose a trimmer framework, a logically coherent definition of "episode" and the semblance of an argument for their semantic choices. In no sense would such a 
procedure represent an explanation for these conflicts or their outcomes to suggest that the complex phenomenon of historical causation can be likened to machinery quite simply undermines our comprehension.

Dynamics of Contention is over-arching in scope, average in conception, and theoretically vacuous. It is also a difficult book to read, as it speaks unabashedly to a narrow circle of specialists conversing with each other in yet another ingroup Esperanto. Just as the reader begins to make sense of a historical narrative, he is entangled in "clusters", "mixes", or "batteries" of "mechanisms" that purportedly drove the episode in question to its destined denouement. (A "microscope" also appears on p. I89). Since the research programme of this group focuses on the past - "familiar processes" - it seems a bit self-serving to adopt a scientific mien with respect to "mixes of mechanisms", producing outcomes when one already knows the outcome, aggregate or otherwise. Unless, that is, they plan to advise policy makers on how to fix the mix in episodes to come. Its approach to political conflict might serve as a manual for aspirant policy advisors and think-tank consultants in Anglo-American academe, a tribe whose contribution to human wisdom is questionable. It is far too taxing for ordinary mortals. 